\title{
Summarizing pure-tone hearing thresholds: The equipollence of components of the audiogram
}

\author{
STANLEY COREN \\ University of British Columbia, Vancouver, British Columbia, Canada
}

\begin{abstract}
The interrelationship among measures of pure-tone hearing level thresholds was explored to determine if a simple summary statistic could be used to describe hearing sensitivity. Pure-tone thresholds from 250,500,1000, 2000, 4000, and $8000 \mathrm{~Hz}$ were assessed for 308 observers. High correlations were observed among the various pure-tone measures, even when separated by several octaves. There was also a high correlation in the sensitivity of the two ears for each observer. The mean threshold, computed including all test frequencies and both ears, was shown to have an average correlation of 0.88 with each of the component measures. This simple average is thus recommended as a valid, yet uncomplicated, summary statistic for reporting the auditory sensitivity of groups.
\end{abstract}

The most typical method of determining an individual's auditory sensitivity involves assessment of hearing thresholds for pure-tone stimuli. Commonly, the testing involves six octaves, usually $250,500,1000,2000,4000$, and $8000 \mathrm{~Hz}$, for each ear separately (e.g., Newby \& Popelka, 1985). The resultant audiogram or threshold profile contains much information that can be valuable for clinical diagnostic purposes, but may represent too finegrained an analysis for a researcher attempting to describe the hearing of large groups of subjects. For such a researcher, the question becomes how one can best summarize the information contained in the audiogram, using the smallest possible number of parameters. This has resulted in some fairly sophisticated analytic procedures based upon principal component analyses (Bamford, Wilson, Atkinson, \& Bench, 1981; Bench, 1983) or curve fitting procedures (Verschuure, van den Wijngaart, Brocaar, \& Nagels, 1985). Although such methodologies are useful, they are often computationally complex and usually involve several parameters or components. For general descriptive purposes (as opposed to specific diagnostic aims), they may also represent a form of statistical "over-kill.",

Recently, Coren (1987) addressed the analogous problem in the visual domain, specifically pertaining to the reporting of visual acuity. He was able to demonstrate that it was possible to reduce the eight most commonly reported indexes of resolution acuity to a simple compos-

This research was supported in part by grants from the British Columbia Health Care Research Foundation and the Natural Sciences and Engineering Research Council of Canada. The author would like to acknowledge the assistance of Wayne Wong, Joan Donelly, Geof Donelly, and Dereck Atha, who assisted in the collection of these data. Requests for reprints should be sent to Stanley Coren, Department of Psychology, 2136 West Mall, University of British Columbia, Vancouver, British Columbia, V6T 1Y7, Canada. ite index that correlated approximately 0.9 with the individual measures, thus providing an easily obtained, single number to summarize the visual acuity of groups of individuals. The study presented below provides an attempt to see if the same sort of data reduction can be usefully applied to audiometric data.

\section{METHOD}

An unselected sample of 308 subjects (179 females and 129 males) was used. Subjects ranged in age from 17 to 92 years $(M=30, \sigma=21.2)$.

The subjects were tested individually in a sound-deadened room. A MAICO (MA-24) audiometer was used to obtain separate air-conduction hearing thresholds for $250,500,1000,2000,4000$, and $8000 \mathrm{~Hz}$ for each ear. Standard audiometric procedures based upon the method of limits were used. Three determinations were taken for each tone, and the median of the three measures served as an estimate of threshold sensitivity.

\section{RESULTS AND DISCUSSION}

A broad range of hearing sensitivity was manifested in the sample. The best ear average threshold (across the six tested frequencies) varied from a high sensitivity of $-2 \mathrm{~dB}$ to a low involving a $93-\mathrm{dB}$ average.

\section{Relationships Among Tonal Thresholds}

As a first analysis, the right ear data was arbitrarily selected to explore the interrelationship among the thresholds for the various pure tones. The right ear tends to be the preferred ear for the majority of subjects (see Coren, Porac, \& Duncan, 1981; Porac \& Coren, 1981). Simple, bivariate correlation coefficients were computed for the thresholds obtained for the various tone frequencies. These are presented in Table 1.

As can be seen from Table 1, there is a very high degree of interrelation among the various pure-tone thresholds. All are highly significant, with $p<.001$. The overall 
Table 1

Correlations Among Pure-Tone Hearing Thresholds as a Function of Test Frequency

\begin{tabular}{ccccccc}
\hline Pure-Tone & \multicolumn{5}{c}{ Pure-Tone Test Frequency (Hz) } \\
\cline { 2 - 7 } Test Frequency (Hz) & 250 & 500 & 1000 & 2000 & 4000 & 8000 \\
\hline 250 & - & & & & & \\
500 & .94 & - & & & & \\
1000 & .87 & .91 & - & & & \\
2000 & .71 & .75 & .85 & - & & \\
4000 & .64 & .68 & .76 & .88 & - & - \\
8000 & .57 & .61 & .69 & .84 & .89 & - \\
\hline
\end{tabular}

Note-Measurements are based upon the right ear of 308 subjects. All correlations are significant with $p<.001$.

average correlation among all of the individual pure-tone sensitivities is 0.77 . The size of the average correlation is strongest for stimuli that are adjacent octaves (average $r=0.89$ ), and diminishes as stimuli become more separated in frequency, with averages of $0.81,0.69,0.63$, and 0.57 for tones separated by $2,3,4$, and 5 octaves, respectively.

\section{Composite Measures of Hearing Sensitivity}

The high degree of association among the individual pure-tone thresholds suggests that an uncomplicated descriptive statistic that could be used to describe overall auditory sensitivity might be the arithmetic mean of the six tones. This value is computed in Table 2 in the column marked "Overall Mean." As can be seen, each of the tones has a very high correlation with the overall mean, averaging 0.89 (with all significant at $p<.01$ ), suggesting that the average over the six tones does provide a fairly homogeneous measure. This can be further demonstrated by assessing the reliability (internal consistency) of the set of individual pure-tone hearing thresholds through computation of Cronbach's (1951) alpha coefficient. The observed alpha is 0.92 , indicating a high internal consistency among the individual pure-tone threshold measures.

One might argue that the correlations between the arithmetic average of the six test-tone thresholds and the individual tonal thresholds represent an inflated measure, due to part-whole confounding caused by the fact that the

Table 2

Correlations Between Composite Measures of Pure-Tone Hearing Thresholds Versus Individual Test Frequencies

\begin{tabular}{cccc}
\hline $\begin{array}{c}\text { Pure-Tone } \\
\text { Test Frequency }(\mathrm{Hz})\end{array}$ & $\begin{array}{c}\text { Overall } \\
\text { Mean }\end{array}$ & $\begin{array}{c}\text { Mean with } \\
\text { Tone Removed }\end{array}$ & $\begin{array}{c}\text { Alpha with } \\
\text { Tone Removed }\end{array}$ \\
\hline 250 & .82 & .77 & .92 \\
500 & .85 & .81 & .92 \\
1000 & .90 & .87 & .91 \\
2000 & .94 & .92 & .89 \\
4000 & .94 & .89 & .89 \\
8000 & .91 & .82 & .93 \\
\hline
\end{tabular}

Note-Overall mean $=$ the arithmetic average of all test frequency thresholds, and alpha estimates internal consistency. Measurements are based upon the right ear of 308 subjects. All correlations are significant with $p<.001$. individual measure is, after all, a part of the overall average. To control for this, separate correlations were computed for each individual tonal threshold against the mean threshold with that particular tone removed. These appear in Table 2 in the column marked "Mean with Tone Removed.' Again, the correlations are extremely high, averaging 0.85 , showing that each individual pure-tone hearing threshold is a very good predictor of the average of the other five pure-tone thresholds that normally appear in an audiogram. This is further verified by computing Cronbach's alpha for each set of tones with the individual tone removed. These appear in the column to the far right in Table 2, which shows that the internal consistency remains quite high (averaging 0.91 ) even if we remove any one tone from the audiometric test group.

The overall conclusion to be reached from the above analyses is that the simple average hearing threshold, across the usual six-octave test range, provides a good predictor of the threshold for any single tone, and hence is probably a useful summary measure.

\section{Interaural Relationships}

Up to now, we have been viewing all of the interrelationships among the measures within a single monaural channel. There appears to be a presumption among many researchers in audition that the two ears are audiometrically independent. Hence, it is not unusual for researchers to report the number of ears tested, rather than the number of subjects. In the vast majority of such instances, subjects are then contributing two auditory threshold profiles to the data pool, and these have generally been statistically treated as if they were no different from a pair of ears from each of two observers.

This situation is similar to that encountered by Coren (1987) in his study of visual acuity measures. Vision researchers have tended to view the acuity of each eye as if it were separate and independent of its contralateral counterpart. Much to Coren's surprise, he found that there was a high degree of similarity between the eyes, with an average interocular acuity correlation at around 0.81 . With this finding in mind, it seemed important to examine whether there were strong similarities between the two ears in terms of hearing threshold level. To accomplish this test, for each subject, each test frequency threshold 
Table 3

Correlations Between Pure-Tone Hearing Thresholds for the Right and Left Ears as a Function of Test Frequency Based upon 308 Subjects

\begin{tabular}{cc}
\hline $\begin{array}{c}\text { Pure-Tone } \\
\text { Test Frequency }(\mathrm{Hz})\end{array}$ & $\begin{array}{c}\text { Correlation Between } \\
\text { Right and Left Ear Thresholds }\end{array}$ \\
\hline 250 & .76 \\
500 & .81 \\
1000 & .86 \\
2000 & .92 \\
4000 & .94 \\
8000 & .93 \\
Overall Mean & .95 \\
\hline
\end{tabular}

Note-All correlations are significant with $p<.001$.

Table 4

Correlations Between the Composite Binaural Average and the Individual Hearing Threshold Measures for the Right and Left Ears for 308 Subjects

Correlation Between Binaural

\begin{tabular}{ccc}
$\begin{array}{c}\text { Pure-Tone } \\
\text { Test Frequency }(\mathrm{Hz})\end{array}$ & \multicolumn{2}{c}{$\begin{array}{c}\text { Correlation Between Binaural } \\
\text { Composite Mean vs. Thresholds }\end{array}$} \\
\cline { 2 - 3 } & Right Ear & Left Ear \\
\hline 250 & .78 & .79 \\
500 & .82 & .84 \\
1000 & .89 & .89 \\
2000 & .94 & .93 \\
4000 & .93 & .93 \\
8000 & .90 & .91 \\
\hline
\end{tabular}

Note - Composite binaural average $=$ pure-tone hearing thresholds averaged across all test frequencies and both ears. All correlations are significant with $p<.001$.

was paired with the corresponding test frequency threshold for the contralateral ear, and product-moment correlations were computed. These appear in Table 3.

As can be seen from Table 3, there is a high correlation between the hearing level thresholds between the two ears, with all correlations significant at $p<.001$. The correlation between the left and right ears averages 0.87 . If we take the overall average hearing level threshold, which we saw above was a reasonable index of composite hearing sensitivity, we find that the correlation between left and right ears rises to a phenomenally high value of 0.95. This suggests that, in the absence of unilateral trauma, the relationship between the two ears is strong enough to account for $90 \%$ of the predictive variance.

Within the context of the search for a simple descriptor of auditory threshold sensitivity, this would suggest that, not only does it make sense to average across all of the test frequencies, but it also makes sense to average across the two ears. When we compute this binaural composite (averaging across the six test frequencies and the left and right ears), we find that it predicts each of the pure-tone hearing level thresholds quite well, with an average correlation of 0.88 , as can be seen from Table 4 .

\section{GENERAL DISCUSSION}

The above set of analyses indicate that it is possible to create a simple composite measure that predicts overall pure-tone hearing thresholds, without the necessity of using complex formulas or multivariate statistical procedures. Based upon the fact that there is such a high degree of similarity among the individual pure-tone thresholds over the six-octave range from 250 to $8000 \mathrm{~Hz}$, and there is a strong similarity between the two monaural channels in terms of their sensitivity, it seems sensible to simply average the pure-tone thresholds across all test frequencies and both ears. This will give a single number that is strongly predictive of any of the individual frequency thresholds, and hence provides a simple, oneparameter description of the sensitivity information contained in the audiogram. Although this simple index will be useful in reporting the auditory sensitivity of groups, it will, of course, lack the diagnostic sensitivity of the fully traced-out audiogram, which allows the researcher to identify patterns of hearing loss, as well as degree. To this extent, this measure is probably not sufficient for some clinical applications, although for most descriptive reporting it should prove quite adequate.

\section{REFERENCES}

Bamford, J. M., Wilson, I. M., Atkinson, D., \& Bench, J. (1981) Pure tone audiograms from hearing-impaired children: II. Predicting speech-hearing from the audiogram. British Journal of Audiology, 15, 3-10.

BENCH, J. (1983). Summarizing pure tone audiograms: An extension of Bamford et al. (1980). British Journal of Audiology, 17, 91-94.

COREN, S. (1987). Reporting the visual acuity of groups: The relationship among alternate measures. American Journal of Optometry \& Physiological Optics, 64, 897-900.

Coren, S., Porac, C., \& DunCan, P. (1981). Lateral behaviors preference in pre-school children and young adults. Child Development, 52, 443-450.

Cronbach, L. J. (1951). Coefficient alpha and the internal structure of tests. Psychometrika, 16, 297-334.

Newby, H. A., \& Popelka, G. R. (1985). Audiology (5th ed.). Englewood Cliffs, NJ: Prentice-Hall.

PORAC, C., \& COREN, S. (1981). Lateral preferences and human behavior. New York: Springer-Verlag.

VerschuUre, J., VAN den WiJngaART, W. S. I. M., BrocaAr, M. P., \& NAGels, M. M. (1985). Audiology, 24, 2-14.

(Manuscript received May 14, 1988.) 